\title{
Status Epilepticus in the Emergency Department, Part 2: Treatment
}

Matthew D. Eisenstat, MD; J. Stephen Huff, MD

\section{In part 1 of this 2-part review, the authors detailed proper diagnosis of seizures in the ED setting. In this concluding article, they focus on appropriate management and treatment options for patients with seizure.}

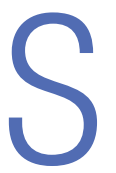
tatus epilepticus is defined as continuous seizure activity for greater than 5 minutes, or repeated episodes of seizures without resolution of the postictal period. When the clinician arrives at the patient's bedside or the emergency medical technician arrives at the scene in the prehospital setting, the patient may be minutes into seizure activity. If the seizure does not immediately resolve, the provider should treat as if status is imminent, if not ongoing. Regardless of setting, if the patient is discovered to be seizing, treatment should be initiated.

It is important to distinguish between provoked and unprovoked seizures, since successful management may require treating an underlying etiology. Although there are as many types of status epilepticus as there are types of seizures, the focus of this review is on generalized convulsive status epilepticus (GCSE).

As a GCSE continues, the overt seizure activity may become subtle-essentially a transformation of generalized status to a state with minimal or no motor movements. Whether or not there is an absence of, or minimal, movement, GCSE still represents a medical emergency, since the excessive neuronal activity causes neuronal injury. An electroencephalogram (EEG) may be required to detect transformed GCSE, which should be suspected if the patient does not exhibit improved mental status within 20 to 30 minutes of convulsive seizure cessation, or if neuromuscular paralysis for intubation has occurred.

\section{Initial Management}

Initial management of seizure patients is consistent with the care of any critical patient in the ED. Assessment of the airway and airway management with endotracheal intubation may be necessary for patients who are apneic or at risk for aspiration, or in whom more conservative management is inadequate.

While placing a patient in the left lateral decubitus position may mitigate aspiration risk, since vomiting is common in a postic-

Dr Eisenstat is a senior resident in emergency medicine, University of Virginia School of Medicine, Charlottesville. Dr Huff is a professor of emergency medicine and neurology, and the director, medical student clerkship, University of Virginia School of Medicine, Charlottesville.

Authors' Disclosure Statement: The authors report no actual or potential conflict of interest in relation to this article.

DOI: 10.12788/emed.2018.0097 
tal state, moving a convulsing patient may be challenging. ${ }^{1}$ Patients should be placed on cardiac monitoring with pulse oximetry if feasible. Intravenous (IV) access should be established if possible, though intramuscular (IM) or other alternative routes for benzodiazepines may be used if obtaining IV access will result in a delay in treatment. ${ }^{2}$

Oxygen should be administered via nonrebreather or bag-valve-mask to patients with apnea to prevent both systemic and cerebral hypoxia. ${ }^{3}$ Since cardiac dysrhythmias with cerebral hypoxia may cause seizure-like activity, it is imperative to check the patient's pulses, blood pressure, and to maintain cardiac monitoring during convulsive episodes. ${ }^{4}$ The patient's glucose levels should be checked upon arrival to determine if the seizure is due to metabolic disturbance, which is an easily reversible cause of seizure. If glucose point-of-care testing is not available, it is reasonable to treat empirically for hypoglycemia.

\section{Emergent Initial Therapy: First-Line Agents \\ Benzodiazepines}

Benzodiazepines are the mainstay of emergent treatment for status epilepticus. The choice of benzodiazepine may be dependent on the clinical setting and availability of IV access or other resources. In the United States, diazepam, lorazepam, and midazolam are the common formulations used for abortive emergent initial therapy.

Diazepam. One of the advantages of diazepam is that it is has the advantage of being water soluble at room temperature, which allows rectal rescue kits for home treatment. Although diazepam is efficacious for status epilepticus, variable pharmacokinetics leading to repeat dosing and further sedation make other benzodiazepines safer.

Lorazepam. Generally accepted as the preferred IV formulation for seizure, lorazepam requires refrigeration and has a short shelf life, making its use challenging in the prehospital setting. When adminis- tered via the IV route, lorazepam works as rapidly as diazepam in treating seizures but with a longer duration of effectiveness, resulting in a decreased need to re-dose or administer an alternative antiepileptic drug (AED). ${ }^{5}$

Midazolam. Newer studies suggest that buccal, intranasal, and IM midazolam may be superior to buccal, intranasal, and IM diazepam in treating GCSE. ${ }^{6}$ The Rapid Anticonvulsant Medication Prior to Arrival Trial demonstrated IM midazolam to be at least as efficacious as IV lorazepam in the prehospital setting for treating GCSE. ${ }^{2}$

\section{Efficacy, Route, and Dosing}

A meta-analysis of all three benzodiazepines in pediatric patients with seizure showed midazolam to have the highest probability of aborting seizure activity, while lorazepam had the least likelihood of causing respiratory depression. ${ }^{7}$ The authors concluded that IV lorazepam and non-IV midazolam were superior to IV and non-IV diazepam in the treatment of pediatric seizures. ${ }^{7}$

A recent retrospective study that analyzed benzodiazepine use in the emergency setting noted underdosing of benzodiazepines in the ED for nonprotocol-driven treatment of status epilepticus, resulting in the increased potential for adverse outcomes and intubations. ${ }^{8}$ Table 1 provides benzodiazepine dosing recommendations by route for adult and pediatric patients, along with potential adverse effects.

\section{Adverse Effects}

As noted previously, benzodiazepines can cause respiratory depression. Anecdotally, respiratory depression is often related to the rate at which the benzodiazepine is administered. For example, most treatment recommendations advise giving IV lorazepam over a 2-minute time period-not as an IV push. ${ }^{7}$

With respect to other adverse effects, it is important to note that IV formulations of diazepam and lorazepam contain propyl- 
Table 1. Benzodiazepines for Status Epilepticus: Dosing Recommendations

\begin{tabular}{|c|c|c|c|}
\hline Medication & Adult Dosing & Pediatric Dosing & Potential Adverse Effects \\
\hline Diazepam & $\begin{array}{l}0.15 \mathrm{mg} / \mathrm{kg} \mathrm{IV} ; \text { maximum } \\
10 \mathrm{mg} \text { per dose. } \\
\text { May redose in } 5 \text { min }\end{array}$ & $\begin{array}{l}\text { PR dosing: } \\
\text { Ages } 2-5 \text { years, } 0.5 \mathrm{mg} / \mathrm{kg} \text {; } \\
\text { Ages } 6-11 \text { years, } 0.3 \mathrm{mg} / \mathrm{kg} \mathrm{PR} \text {; } \\
\text { Age > } 12 \text { years, } 0.2 \mathrm{mg} / \mathrm{kg}\end{array}$ & $\begin{array}{l}\text { Respiratory depression; } \\
\text { hypotension and bradycardia } \\
\text { (associated with propylene } \\
\text { diluent) }\end{array}$ \\
\hline Lorazepam & $\begin{array}{l}0.1 \mathrm{mg} / \mathrm{kg} \mathrm{IV} ; \text { max of } 4 \mathrm{mg} \\
\text { per dose; may redose in } 10 \mathrm{~min}\end{array}$ & $\begin{array}{l}0.1 \mathrm{mg} / \mathrm{kg} \mathrm{IV} \text {; max of } 4 \mathrm{mg} \text { per } \\
\text { dose; may redose in } 10 \mathrm{~min}\end{array}$ & $\begin{array}{l}\text { Respiratory depression; } \\
\text { hypotension and bradycardia } \\
\text { (associated with propylene } \\
\text { diluent) }\end{array}$ \\
\hline Midazolam & $\begin{array}{l}0.2 \mathrm{mg} / \mathrm{kg} \mathrm{IV}, \mathrm{IM} ; \text { max of } 10 \mathrm{mg} \\
\text { may redose in } 10 \mathrm{~min}\end{array}$ & $\begin{array}{l}10 \mathrm{mg} \text { IM > } 40 \text { kg, } \\
5 \mathrm{mg} \mathrm{IM} \mathrm{13-40} \mathrm{kg,} \\
0.2 \mathrm{mg} / \mathrm{kg} \mathrm{IN}, \\
0.5 \mathrm{mg} / \mathrm{kg} \text { buccally }\end{array}$ & $\begin{array}{l}\text { Respiratory depression; } \\
\text { hypotension }\end{array}$ \\
\hline
\end{tabular}

Abbreviations: IM, intramuscularly; IN, intranasally; IV, intravenously; PR, rectally.

ene glycol as a diluent, which may lead to hypotension and bradycardia, especially when large volumes are infused over short periods of time. ${ }^{9}$

\section{Second-Line Agents}

While emergent initial therapy with benzodiazepines is well established, the preferred second-line agent, or urgent control therapy, continues to be a subject of controversy due to a lack of conclusive evidence for a superior agent. ${ }^{10}$ The Established Status Epilepticus Treatment Trial (ESETT) is currently conducting a head-to-head study to determine if any of the commonly used second-line agents (ie, fosphenytoin, levetiracetam, valproic acid) will prove to be more efficacious. ${ }^{11}$ Recently, the adult arm of the ESETT trial was halted due to futility.

All patients without an identifiable secondary cause of GCSE (eg, hypoglycemia, hyponatremia, hypocalcemia) should be started on a second-line agent. Treatment with a second-line agent provides two benefits: First, patients who experience resolution of seizure activity may rapidly attain therapeutic levels of AEDs, which may be sustained through maintenance therapy; and second, the second-line treatment may abort refractory cases of status. ${ }^{12}$ Table 2 provides dosing recommendations for second-line agents.

\section{Phenytoin and Fosphenytoin}

Phenytoin and the newer prodrug fosphenytoin are a mainstay urgent-control therapy for emergency physicians (EPs) and neurologists alike. In one of the few head-to-head studies of AEDs, ${ }^{13}$ phenytoin did not perform as well as the other study agents (diazepam, lorazepam, and phenobarbital); however, generalizability from this study is limited. Fosphenytoin continues to be an efficacious choice for secondline treatment of AED.

Fosphenytoin, a water-soluble prodrug of phenytoin, is given preferentially over IV phenytoin due to its decreased risk of cardiovascular (CV) side effects and more rapid administration. ${ }^{14}$ Moreover, fosphenytoin is compatible with most IV fluids 
Table 2. Urgent-Control Therapeutic Agents for Status Epilepticus: Dosing Recommendations ${ }^{a}$

\begin{tabular}{ll}
\hline Medication & Dosing \\
\hline Phenytoin/Fosphenytoin & $20 \mathrm{mg}$ (or PE)/kg over $10 \mathrm{~min}$ \\
\hline $\begin{array}{l}\text { Valproic Acid } \\
\text { Levetiracetam }\end{array}$ & $40 \mathrm{mg} / \mathrm{kg}$ over $10 \mathrm{~min}$ \\
\hline $\begin{array}{l}\text { Phenobarbital } \\
\text { aAlthough these agents are commonly used in practice for treating generalized convulsive } \\
\text { status epilepticus (GCSE), none are approved by the US Food and Drug Administration } \\
\text { for GCSE. }\end{array}$
\end{tabular}

(eg, dextrose, lactated Ringer's solution, normal saline [NS]), whereas phenytoin is only compatible with NS. For convenience, fosphenytoin is dosed in phenytoin equivalents $(\mathrm{PE} / \mathrm{kg})$ —eg, administration of $20 \mathrm{PE} / \mathrm{kg}$ over 10 minutes is a potential loading dose for fosphenytoin.

\section{Valproic Acid}

Valproic acid has become a favored second-line agent for many providers due to its relatively safe profile and rapid infusion time. Most studies have shown IV valproic acid is at least as effective as phenytoin, but data continue to be somewhat weak and most of the studies are uncontrolled. ${ }^{15}$

Hepatotoxicity is generally only associated with long-term use of valproic acid, but it remains reasonable to abstain from using this agent in patients with preexisting hepatic disease. Valproic acid toxicity can lead to somnolence, ataxia, seizures, and coma with marked hyperammonemia. ${ }^{16}$

\section{Levetiracetam}

Intravenous levetiracetam is becoming a more commonly used drug both for emergent initial treatment of seizure and as a maintenance therapy. While data on levetiracetam are limited, a few studies tout the efficacy and safety of IV loading to abort GCSE.
In observational studies, levetiracetam appears to have similar efficacy to other AEDs and may be more beneficial in early therapy. ${ }^{17}$ An ongoing current study, The Emergency Treatment With Levetiracetam or Phenytoin in Status Epilepticus trial, is examining a prospective cohort of pediatric patients comparing levetiracetam against phenytoin. ${ }^{18}$

Levetiracetam is generally considered safe. The most commonly reported side effects are dizziness, somnolence, nausea, and brief transaminitis. ${ }^{19}$ Levetiracetam has also been associated with neuropsychiatric exacerbations. ${ }^{20}$

\section{Phenobarbital}

Intravenous phenobarbital has been used as an urgent-control therapy for seizure with good efficacy, even in recent years. ${ }^{21}$ Despite this, phenobarbital may cause profound CV depression necessitating the use of vasopressors. ${ }^{22}$ Large-dose phenobarbital can be used to induce coma in patients, although this should not be attempted without the guidance of a neurologist. While phenobarbital can be used safely in certain circumstances, its use has fallen out of favor in the ED due to the availability of safer alternative options.

\section{Refractory Status Epilepticus}

If after receiving two AEDs, a patient continues to demonstrate seizure activity on physical examination or EEG, she or he is considered to have refractory status epilepticus, which is a medical emergency. Patients in refractory status epilepticus will likely require a continuous infusion of an AED as well as definitive airway management as a result of either seizure or continuous treatment. In rare cases, some patients will continue to seize despite continuous treatment. Such patients are considered to have super refractory status epilepticus, which is defined as continuing seizure activity despite treatment with general anesthetics for more than 24 hours. This condition is beyond the scope of tra- 
ditional EP practice, who in this scenario would consult emergently with neurology or critical care services.

Treatment for patients with refractory status epilepticus includes propofol, high-dose midazolam, and ketamine. As previously noted, patients with refractory seizure likely will require airway management; therefore, consultation with neurology or critical care services is indicated.

\section{Propofol}

Propofol, a sedative-hypnotic agent that activates both $\gamma$-aminobutyric acid and $\mathrm{N}$ methyl-D-aspartate receptors, is commonly given to patients with refractory status epilepticus. While head-to-head reviews have not shown propofol to be superior to phenobarbital or midazolam in treating refractory seizure, it is a drug that is familiar to most EPs. ${ }^{23}$ Midazolam or propofol are typically given to patients in the ED who require intubation with sedation.

With respect to side effects, propofol can cause dose-limiting hypotension. In addition, propofol infusion syndrome leading to lactic acidosis and cardiac dysfunction in patients receiving long-term propofol infusion. ${ }^{24}$ One possible infusion dose is $0.5-1 \mathrm{mg} / \mathrm{kg}$ loading dose with a continuous infusion of $2 \mathrm{mg} / \mathrm{kg} / \mathrm{h} \mathrm{IV}$.

\section{High-Dose Midazolam}

High-dose midazolam may be given as an alternative to propofol as some studies have shown its efficacy in treating refractory status epilepticus. ${ }^{25}$ Continuous lowdose infusions of midazolam $(0.2 \mathrm{mg} / \mathrm{kg} / \mathrm{h})$ have been given to patients in the neurological intensive care unit (ICU); however, there are some data to support treating with a higher dose $(\geq 0.4 \mathrm{mg} / \mathrm{kg} / \mathrm{h}){ }_{.}{ }^{25}$ In one single-center retrospective trial, post discharge all-cause mortality was lower in the cohort group that received the higher dose infusion ( $40 \%$ vs $62 \%$ ). ${ }^{25}$ Although higher rates of hypotension were noted in the high-dose group, it did not appear to affect mortality.

\section{Ketamine}

Ketamine has become a valued anesthetic in emergency medicine, and EPs have become comfortable with its dosing and safety profile. While animal studies on ketamine are promising to treat status epilepticus, human data are limited and often extrapolated from retrospective ICU data. Many patients are placed on a ketamine infusion multiple days into status epilepticus, and for this reason, ketamine is not recommended as a second-line abortive drug in the ED. ${ }^{26}$

\section{Alternative Treatments and Super Refractory GCSE}

In cases of patients with seizure activity ongoing beyond conventional therapy, other methods have been attempted to cease seizure activity and achieve burst suppression on EEG. None of these treatments is in the purview of the EP and should only be undertaken by a neurologist.

Two pharmacologic agents that have some limited efficacy include lacosamide and topiramate. Isoflurane is the most commonly used inhaled anesthetic. ${ }^{27}$ Thiopental and pentobarbital are barbiturate anesthetics which are used in super refractory GCSE. Barbiturates have a desirable theoretical neuroprotective effect, but are limited by their CV depression at high doses. ${ }^{28}$ Vagus nerve stimulation, induced hypothermia, transcranial magnetic stimulation, and neurosurgical intervention have all been attempted with varying degrees of success in select patients. ${ }^{29}$

\section{Eclampsia and Seizures During Pregnancy}

Treating a pregnant patient with status epilepticus presents a unique challenge in the ED. The EP must weigh the importance of aborting seizure activity with the possibility of teratogenic effects. All AEDs must be used carefully, but valproic acid and phenytoin are potent teratogens and should be avoided in this patient population. Most evidence points to safety with 
exposure to benzodiazepines during pregnancy. ${ }^{30}$ Eclampsia must be considered in patients who may be pregnant or recently pregnant; magnesium should be used with or without the use of benzodiazepines in these patients.

\section{Summary}

The diagnosis and treatment of status epilepticus in the ED can be challenging. While there is a multitude of first-, second-, and third-line agents available to treat this condition, choosing the correct therapy for a patient can be daunting, and evidence of which treatment is superior can be lacking. However, the judicious use of benzodiaz-

\section{References}

1. DeToledo JC, Lowe MR. Seizures, lateral decubitus, aspiration, and shoulder dislocation: time to change the guidelines? Neurology. 2001;56(3):290-291. doi:10.1212/wnl.56.3.290.

2. Silbergleit R, Lowenstein D, Durkalski V, et al; Neurological Emergency Treatment Trials (NETT) Investigators. RAMPART (Rapid Anticonvulsant Medication Prior to Arrival Trial): a double-blind randomized clinical trial of the efficacy of intramuscular midazolam versus intravenous lorazepam in the prehospital treatment of status epilepticus by paramedics. Epilepsia. 2011;52(Suppl 8):45-47. doi:10.1111/j.1528-1167.2011.03235.x

3. Kreisman NR. Cerebral hypoxia during repetitive seizures. In: Somjen G, ed. Advances in Behavioral Biology: Mechanisms of Cerebral Hypoxia and Stroke. Vol 35. Boston, MA: Springer; 1988:139-149.

4. Van der Lende M, Surges R, Sander JW, Thijs RD. Cardiac arrhythmias during or after epileptic seizures. J Neurol Neurosurg Psychiatry. 2016;87(1):6974. doi:10.1136/jnnp-2015-310559.

5. Appletan R, Sweeney A, Choonara I, Robson J, Molyneux E. Lorazepam versus diazepam in the acute treatment of epileptic seizures and status epilepticus. Dev Med Child Neurol. 1995;37(8):682-688. doi:10.1111/j.1469-8749.1995.tb15014.x.

6. McMullan J, Sasson C, Pancioli A, Silbergleit R. Midazolam versus diazepam for the treatment of status epilepticus in children and young adults: a meta-analysis. Acad Emerg Med. 2010;17(6):575-582. doi:10.1111/j.1553-2712.2010.00751.x.

7. Zhao ZY, Wang HY, Wen B, Yang ZB, Feng K, Fan JC. A comparison of midazolam, lorazepam, and diazepam for the treatment of status epilepticus in children: a network metaanalysis. J Child Neurol. 2016;31(9):1093-1107. doi:10.1177/0883073816638757.

8. Braun J, Gau E, Revelle S, Byrne L, Kumar A. Impact of non-guideline-based treatment of status epilepticus. J Neurol Sci. 2017;382:126-130. doi:10.1016/j. jns.2017.09.031.

9. Pillai U, Hothi JC, Bhat ZY. Severe propylene glycol toxicity secondary to use of anti-epileptics. Am J Ther. 2014;21(4):e106-e109. doi:10.1097/ MJT.0b013e31824c407d.

10. Berkowitz R, Koyfman A. What is the best first-line epines continues to be the primary treatment option. If status epilepticus persists, alternative agents and airway management may be necessary. The goal of treatment is to abort seizure-like activity observed on physician examination or EEG. It is important to remember that symptoms of status epilepticus can be subtle (eg, mild twitching, eye deviation), particularly when airway management is required since neuromuscular blockade can mask overt symptoms. Consultation with neurology and critical care colleagues should be initiated early; when such consultation is not available, the EP should consider patient transfer to an appropriate facility.

agent for benzodiazepine-resistant convulsive status epilepticus? Ann Emerg Med. 2014;64(6):656-657 doi:10.1016/j.annemergmed.2014.04.017.

11. Established Status Epilepticus Treatment Trial. U.S. National Library of Medicine. ClinicalTrials. gov Web site. https://clinicaltrials.gov/ct2/show/ NCT01960075. Accessed June 7, 2018.

12. O'Phelan KH, Miller CM. Emergency neurological life support: third edition, updates in the approach to early management of a neurological emergency. Neurocrit Care. 2017;27(Suppl 1):1-3. doi:10.1007/ s12028-017-0448-x.

13. Treiman DM, Meyers PD, Walton NY, et al. A comparison of four treatments for generalized convulsive status epilepticus. Veterans Affairs Status Epilepticus Cooperative Study Group. $N$ Engl J Med. 1998;339(12):792-798. doi:10.1056/ NEJM199809173391202.

14. Thomson A. Fosphenytoin for the treatment of status epilepticus: an evidence-based assessment of its clinical and economic outcomes. Core Evid. 2005;1(1):65-75. doi:10.2147/ce.s6408.

15. Kanner AM. Intravenous valproate for status epilepticus...an effective, yet still merely empirical alternative! 2008;8(3):66-67. doi:10.1111/j.15357511.2008.00240.x.

16. Mishra D, Jain R, Juneja M, Chakrabarty B. Valproate associated hyperammonemic encephalopathy. J Pediatr Neurol. 2015;9(1):93-95. doi:10.3233/jpn-2010-0437.

17. Aiguabella M, Falip M, Villanueva V, et al. Efficacy of intravenous levetiracetam as an add-on treatment in status epilepticus: a multicentric observational study. Seizure. 2011;20(1):60-64. doi:10.1016/j. seizure.2010.10.009.

18. Lyttle MD, Gamble C, Messahel S, et al; supported by Paediatric Emergency Research in the United Kingdom \& Ireland (PERUKI). Emergency treatment with levetiracetam or phenytoin in status epilepticus in children-the EcLiPSE study: study protocol for a randomised controlled trial. Trials. 2017;18(1):283. doi:10.1186/s13063-017-2010-8.

19. Uges JW, van Huizen MD, Engelsman J, et al Safety and pharmacokinetics of intravenous levetiracetam infusion as add-on in status epilepticus. Epilepsia. 2009;50(3):415-421. doi:10.1111/j.1528-1167.2008.01889.x. 
20. Afazal U, Oostema JA, Smith B. Emergency department initiation of levetiracetam for seizure: a cohort study examining psychiatric risk assessment and counseling. Ann Emerg Med. 2013;62(4):S131. doi:10.1016/j.annemergmed.2013.07.194.

21. Muramoto E, Mizobuchi M, Sumi Y, et al. Efficacy of intravenous phenobarbital treatment for status epilepticus. Brain Nerve. 2013;65(8):983-987.

22. Wijdicks EFM. Status epilepticus. In: The Practice of Emergency and Critical Care Neurology. New York, NY: Oxford University Press; 2010:558-559.

23. Claassen J, Hirsch LJ, Emerson RG, Mayer SA. Treatment of refractory status epilepticus with pentobarbital, propofol, or midazolam: a systematic review. Epilepsia. 2002;43(2):146-153. doi:10.1046/j.15281157.2002.28501.x.

24. Choi YJ, Kim MC, Lim YJ, Yoon SZ, Yoon SM, Yoon HR. Propofol infusion associated metabolic acidosis in patients undergoing neurosurgical anesthesia: a retrospective study. J Korean Neurosurg Soc.

2014;56(2):135-140. doi:10.3340/jkns.2014.56.2.135

25. Fernandez A, Lantigua H, Lesch C, et al. High-dose midazolam infusion for refractory status epilepti- cus. Neurology. 2013;82(4): 359-365. doi:10.1212/ wnl.0000000000000054.

26. Dorandeu F. Ketamine for the treatment of (super) refractory status epilepticus? Not quite yet. Expert Rev Neurother. 2017;17(5):419-421. doi:10.1080/147 37175.2017.1288099.

27. Zeiler FA, Zeiler KJ, Teitelbaum J, Gillman LM, West M. Modern inhalational anesthetics for refractory status epilepticus. Can J Neurol Sci. 2015;42(2):106115. doi:10.1017/cjn.2014.121.

28. Shorvon S, Ferlisi M. The treatment of super-refractory status epilepticus: a critical review of available therapies and a clinical treatment protocol. Brain. 2011;134(10):2802-2818. doi:10.1093/brain/awr215.

29. Winkler PA. Surgical treatment of status epilepticus: a palliative approach. Epilepsia. 2013;54(Suppl 6):68-71. doi:10.1111/epi.12282

30. Eros E, Czeizel AE, Rockenbauer M, Sorensen HT, Olsen J. A population-based case-control teratologic study of nitrazepam, medazepam, tofisopam, alprazolum and clonazepam treatment during pregnancy. Eur J Obstet Gynecol Reprod Biol. 2002;101(2):147154. doi:10.1016/s0301-2115(01)00545-0. 